\begin{tabular}{c} 
International Journal of Advanced Chemistry, 2(2)(2014) $139-142$ \\
International Journal of Advanced Chemistry \\
Journal home page: $\begin{array}{c}\text { www.sciencepubco.com/index.php/IJAC } \\
\text { doi: } 10.14419 / \text { ijac.v2i2.3272 } \\
\text { Research Paper }\end{array}$ \\
\hline
\end{tabular}

\title{
Inhibition effect of potassium iodide on the corrosion of carbon steel (XC 38) in acidic medium
}

\author{
Tarik Attar $^{1,2}$ *, Lahcène Larabi ${ }^{1}$, Yahia Harek ${ }^{1}$ \\ ${ }^{1}$ Laboratory of Analytical Chemistry and Electrochemistry, Department of chemistry, \\ Faculty of sciences, University Abou-Bekr Belkaïd, Tlemcen 13000, Algeria \\ ${ }^{2}$ University Center of Naama 4500, Algeria \\ *Corresponding author E-mail: att.tarik@gmail.com
}

\begin{abstract}
The effect of potassium iodide (KI) on the corrosion of carbon steel (XC38) in $0.5 \mathrm{M} \mathrm{H} 2 \mathrm{SO} 4$ has been investigated in relation to the concentration of the inhibitor by weight loss measurement. It was found that the inhibition efficiency increases with an increase in concentration of inhibitors and temperature. The effect of temperature on the corrosion behavior with the addition of optimal concentration of KI was studied in the temperature range 293-323 K. The adsorption of the inhibitor on the XC38 surface is in agreement with Temkin adsorption isotherm. On the bases of thermodynamic adsorption parameters, it can be interpreted that the adsorption of this inhibitor on the carbon steel surface takes place through both chemical and physical adsorption.
\end{abstract}

Keywords: Corrosion Inhibition, Weight Loss, Carbon Steel, Adsorption Isotherm, Thermodynamic Parameters.

\section{Introduction}

Corrosion problems have received a considerable amount of attention because of their attack on materials (Abd El-Maksoud 2008). The use of inhibitors is one of the best methods of protecting metals against corrosion involves the use of inhibitors which are substances that slow down the rate of corrosion (Trabanelli 1991, Ali et al. 2003). A corrosion inhibitor is a substance which is added in small amounts to a corrosive medium to reduce its ability for corrosion (Dananjaya 2012). The selection of inhibitor is controlled by its capacity to inhibit corrosion of the substrate material, its environmental side effects and its economic availability. The use of inorganic inhibitors as an alternative to organic compounds is based on the possibility of degradation of organic compounds with time and temperature (Antonijevic \& Petrovic 2008, Tomić 2010). Carbon steel is a very prominent material of construction and frequently comes in contact with aqueous solution, which may be acidic in nature, as a part of industrial process (Deyab 2007). The investigation of corrosion of carbon steel is always a subject of high theoretical as well as practical interest (Fouda \& Badr 2013). The study of carbon steel corrosion phenomena has become important particularly in acidic media because of the increased industrial applications of acid solutions (Hamdy \& El-Gendy 2013). Among the acid solutions, sulfuric acid is one of the most aggressive acids for iron and its alloys and is often used during cleaning, pickling, descaling, acidizing, and so forth (Poornima et al. 2013, Kumar \& Shetty 2013). Temperature dependence of the inhibitor efficiency and the comparison of the obtained thermodynamic data of the corrosion process both in absence and presence of inhibitors lead to some conclusions concerning the mechanism of inhibiting action (Noor 2007, Hammouti et al. 2011, Khadraoui 2014).

The adsorption process depends upon the nature and surface charge of the metal, the type of aggressive media, the structure of the inhibitor and the nature of its interaction with the metal surface
(Solmaz et al. 2008, Chen 2011, Zaafarany 2013). The adsorption of the inhibitors can be described by two main types of interaction: physical adsorption and chemisorptions (Larabi et al. 2004, 2006).

In the present work, the inhibitive effectiveness of potassium iodide has been studied in retarding corrosion of carbon steel (XC38) in $0.5 \mathrm{M} \mathrm{H}_{2} \mathrm{SO}_{4}$. Weight loss measurements were used to know the effect of inhibitor concentration, exposure time and temperature.

\section{Materials and methods}

\subsection{Materials}

Carbon steel (XC38) were used for the weight loss measurement contains $\mathrm{C}=0.15-0.35 \%, \mathrm{Mn}=0.5-1 \%, \mathrm{Si}=0.15-0.35 \%, \mathrm{P}=$ $0.015-0.035 \%, \mathrm{~S}=0.035 \%$, and iron is the remainder.

The electrode was polished using different grades of emery papers and degreased. The specimens were weighed by electronic digital analytical balance with five decimal accuracy before and after exposure.

\subsection{Weight loss method}

A known weight of carbon steel coupon was immersed in $100 \mathrm{ml}$ of the test solution in an open beaker. The beaker was transferred into a water bath maintained at $303 \mathrm{~K}$. Weight loss measurements were performed on carbon steel sample by immersing it in the absence and presence of different concentrations of inhibitor in $0.5 \mathrm{M} \mathrm{H}_{2} \mathrm{SO}_{4}$ solution. The inhibition efficiency (\% IE) of the inhibitor, degree of surface coverage $(\theta)$ and corrosion rates $(w)$ were determined from the weight loss results, using equations (1), (2), and (3) respectively: 


$$
\begin{aligned}
& \mathrm{IE}(\%)=\left[\left(\mathrm{w}_{\text {corr }}-\mathrm{w}_{\text {inh }}\right) / \mathrm{w}_{\text {corr }}\right] \times 100 \\
& \mathrm{~W}=\left(\mathrm{m}_{1}-\mathrm{m}_{2}\right) / \mathrm{S} . \mathrm{t} \\
& \theta=1-\mathrm{w}_{\text {inh }} / \mathrm{w}_{\text {corr }}
\end{aligned}
$$

Where $m_{1}$ and $m_{2}$ are the weight losses of the specimen before and after corrosion, $S$ is the area of the specimen, $t$ is the time of immersion and $\mathrm{w}_{\text {corr }}, \mathrm{w}_{\mathrm{inh}}$ are the corrosion rates in the presence and absence of inhibitor respectively.

\section{Results and discussion}

\subsection{Effect of inhibitor concentration}

The effect of the inhibition efficiencies obtained from the weight loss with different inhibitor concentrations are presented in Figure 1. It is clear from data in Figure 1 that the increase of the inhibitors concentrations from $10^{-4}$ to $10^{-3} \mathrm{M}$ decreased the corrosion rates of the carbon steel in $0.5 \mathrm{M} \mathrm{H}_{2} \mathrm{SO}_{4}$ solution. The results show that inhibition efficiency increases as the concentration of inhibitor. The maximum inhibition efficiency for potassium iodide inhibitor was found to be about $48.46 \%$.

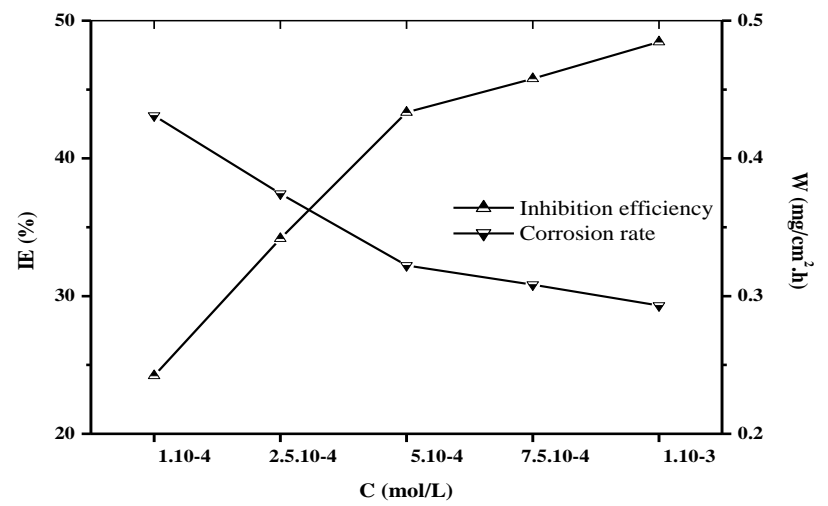

Fig. 1: Variation of Inhibition Efficiency and Corrosion Rate Vs Inhibitor Concentration for Carbon Steel after 2 Hrs of Exposure.

\subsection{Effect of exposure time}

Immersion time analysis of carbon steel samples in the acidic solutions with and without the optimal concentration of the inhibitor was performed using weight loss at $303 \mathrm{~K}$. The weight loss of $\mathrm{XC} 38$ steel in $0.5 \mathrm{M} \mathrm{H}_{2} \mathrm{SO}_{4}$ is nearly varied linearly with immersion period in the absence and presence of different concentrations of potassium iodide as shown in Figure 2.

The variation of the inhibition efficiency of this inhibitor with time is shown in Figure 3. This shows that inhibition efficiency of the potassium iodide was increased with increasing immersion time. These results indicate a stabilization of the inhibition rate from 2 hours of immersion.

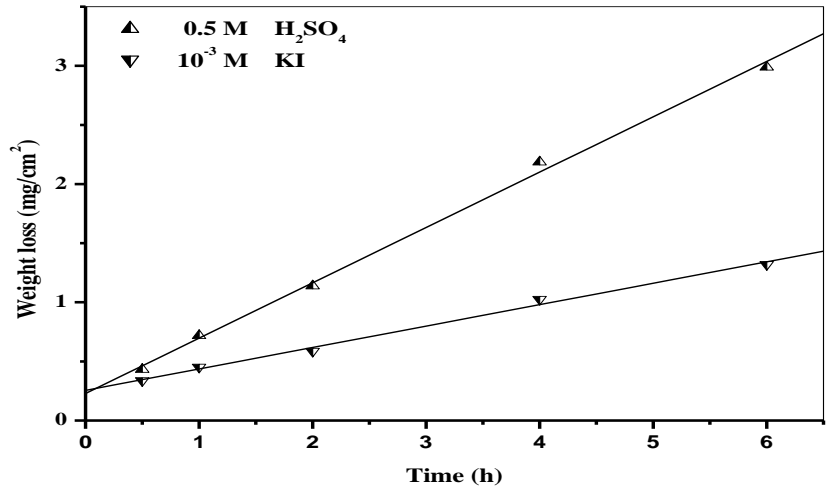

Fig. 2: Weight Loss as a Function of Immersion Time of XC38 Steel in $0.5 \mathrm{M} \mathrm{H}_{2} \mathrm{SO}_{4}$ without and With $10^{-3} \mathrm{M}$ of KI At $303 \mathrm{~K}$

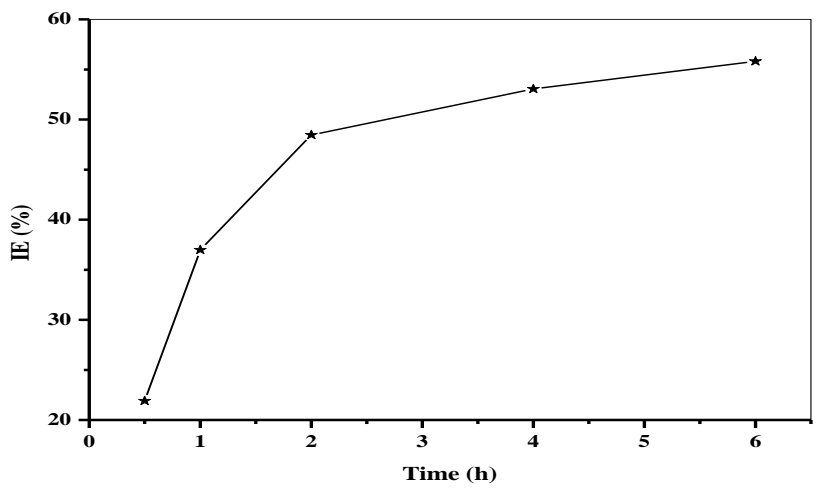

Fig. 3: Variation of Inhibition Efficiency of KI At $10^{-3} \mathrm{M}$ With Immersion Time.

\subsection{Effect of temperature}

The effect of rising temperature on the corrosion rate of carbon steel in $0.5 \mathrm{M} \mathrm{H}_{2} \mathrm{SO}_{4}$ containing $10^{-3} \mathrm{M}$ of potassium iodide was studied in temperature range from 20 to $50^{\circ} \mathrm{C}$ by weight loss measurements. Table 1 shows the effect of temperature on the corrosion rate of carbon steel in absence and presence of inhibitor. It is evident from this Table that inhibition efficiency increases with increasing temperature.

Table 1: Effect of Temperature on the Corrosion Rate and Inhibition Efficiency for the Corrosion of XC (38) in $0.5 \mathrm{M} \mathrm{H}_{2} \mathrm{SO}_{4}$ Solution in Absence and Presence of Inhibitors.

\begin{tabular}{llll}
\hline $\mathrm{T}(\mathrm{K})$ & $\mathrm{w}_{0}\left(\mathrm{mg} / \mathrm{cm}^{2} . \mathrm{h}\right)$ & $\mathrm{W}_{\text {inh }}\left(\mathrm{mg} / \mathrm{cm}^{2} . \mathrm{h}\right)$ & $\mathrm{IE}(\%)$ \\
\hline 293 & 0.26876 & 0.18264 & 32.04 \\
303 & 0.56877 & 0.29313 & 48.46 \\
313 & 1.31803 & 0.64454 & 51.09 \\
323 & 3.39625 & 1.22182 & 64.02 \\
\hline
\end{tabular}

\subsection{Adsorption isotherm}

To understand the mechanism of corrosion inhibition, the adsorption behavior of the inhibitors adsorbents on the metal surface must be known. The most usually used adsorption isotherms are Langmuir, Temkin, Frumkin and other various isotherms (Shukla 2011, Hmamou et al. 2012). The adsorption is also influenced by the structure and the charge of the metal surface, and the type of testing electrolyte (El Ashry et al. 2006, Kissi et al. 2006, Obot et al. 2009). Adsorption isotherms provide information about the interaction of the adsorbed molecules with the electrode surface (Noor \& Al-Moubaraki 2008). This absorption isotherm can be put in linear form from Equation 4 as follows (Bilgic \& Caliskan 2001, Umoren et al. 2008, Ebenso et al. 2009):

$\mathrm{K}_{\mathrm{ads}} \mathrm{C}_{\mathrm{inh}}=\exp (-2 \mathrm{a} \theta)$

$\operatorname{Ln}\left(\mathrm{C}_{\text {inh }}\right)=-2 \mathrm{a} \theta-\ln \left(\mathrm{K}_{\mathrm{ads}}\right)$

Where $\mathrm{C}_{\mathrm{inh}}$ is the concentration of inhibitor, $\mathrm{K}_{\mathrm{ads}}$ is the equilibrium constant of adsorption, a is lateral interaction parameter which describe the molecular interactions in the adsorbed layer.

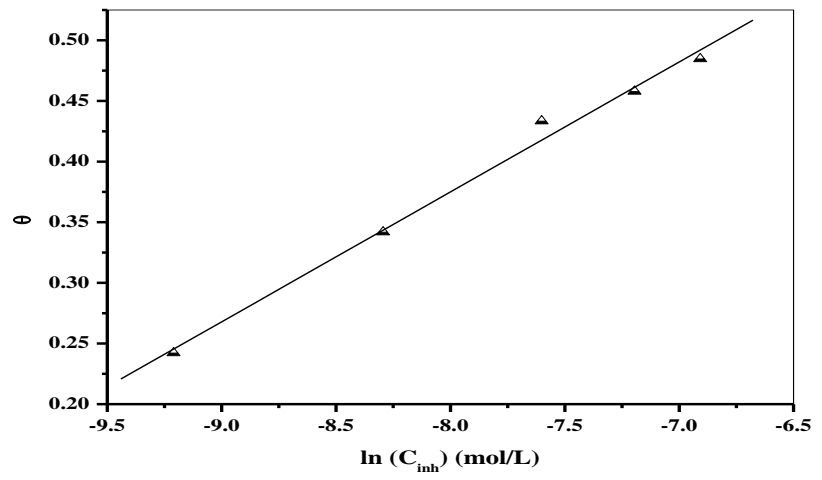

Fig. 4: Temkin Adsorption of KI on the Carbon Steel Surface in $0.5 \mathrm{M}$ $\mathrm{H}_{2} \mathrm{SO}_{4}$ Solution. 
Plots of $\theta$ against $\ln \left(\mathrm{C}_{\mathrm{inh}}\right)$, as presented in Figure 4, gave linear relationship, which shows that adsorption data fitted Temkin adsorption isotherm. Adsorption parameters obtained from Temkin adsorption isotherms are recorded in Table 2 . The values of attractive parameter (a) are negative, indicating that repulsion exists in the adsorption layer.

The equilibrium constant $\mathrm{K}_{\mathrm{ads}}$ is related to the standard free energy of adsorption $\left(\Delta \mathrm{G}_{\mathrm{ads}}\right)$ with the following equation (Fekry \& Ameer 2010):

$\mathrm{K}_{\mathrm{ads}}=(1 / 55.5) \exp \left(-\Delta \mathrm{G}_{\mathrm{ads}} / \mathrm{RT}\right)$

Where $\mathrm{R}$ is the gas constant and $\mathrm{T}$ is the absolute temperature. The constant value of 55.5 is the concentration of water in solution in $\mathrm{mol} / \mathrm{dm}^{3}$ (Olivares et al. 2006).

Table 2: Adsorption Parameters from Temkin Isotherm for XC38 in $0.5 \mathrm{M}$ $\mathrm{H}_{2} \mathrm{SO}_{4}$ Solutions Containing $10^{-4} \mathrm{M}$ Inhibitor At $303 \mathrm{~K}$

\begin{tabular}{lllll}
\hline Inhibitor & $\mathrm{R}^{2}$ & $\mathrm{~A}$ & $\mathrm{~K}_{\text {ads }}$ & $\Delta \mathrm{G}_{\text {ads }}$ \\
\hline $\mathrm{KI}$ & 0.99 & -4.63 & $9.59 \times 10^{4}$ & -39.01 \\
\hline
\end{tabular}

The negative values of $\Delta \mathrm{G}_{\mathrm{ads}}$ showed that the adsorption of inhibitor molecules on the metal surface is spontaneous (Dabrowski 2001). If the values of is in the order of $-20 \mathrm{~kJ} / \mathrm{mol}$ or less this would indicate a physical adsorption, while those values of -40 $\mathrm{kJ} / \mathrm{mol}$ or higher imply chemical adsorption. We can conclude that adsorption acts simultaneously by chemisorptions and physical adsorption (Dahmani et al. 2010).

\subsection{Thermodynamic parameters}

Kinetic and thermodynamic parameters of dissolution process are important to understand the inhibition mechanism, It has been reported that the natural logarithm of the corrosion rate is a linear function with $1 / T$, where $T$ is the absolute temperature, for the corrosion of carbon steel in acidic conditions (Okafor et al. 2008, Quraishi et al. 2010).

The apparent activation energy $E_{a}$ for carbon steel corrosion in uninhibited and inhibited acid solution was evaluated from Arrhenius equation (Quraishi \& Khan 2005, Singh et al. 2012):

$\operatorname{Ln}(w)=\left(-E_{a} / R T\right)+A$

Where $\mathrm{w}$ is the corrosion rate determined from gravimetric measurements, A is the Arrhenius frequency factor, $\mathrm{R}$ is the molar gas constant and $\mathrm{T}$ is the absolute temperature.

The $E_{a}$ values were calculated from the slope, equals to $-E_{a} / R$ of each straight line. Arrhenius plots are shown in Figure 5.

The apparent activation energy obtained for the corrosion process in the inhibitor-free, uninhibited acid solution was found to be 66.34 and $50.94 \mathrm{~kJ} / \mathrm{mol}$ in presence of the inhibitor. The energy barrier of the corrosion reaction decreased in the presence of the inhibitor, which can be due to the adsorption of the inhibitor on the steel surface (Valle-Quitana 2014).

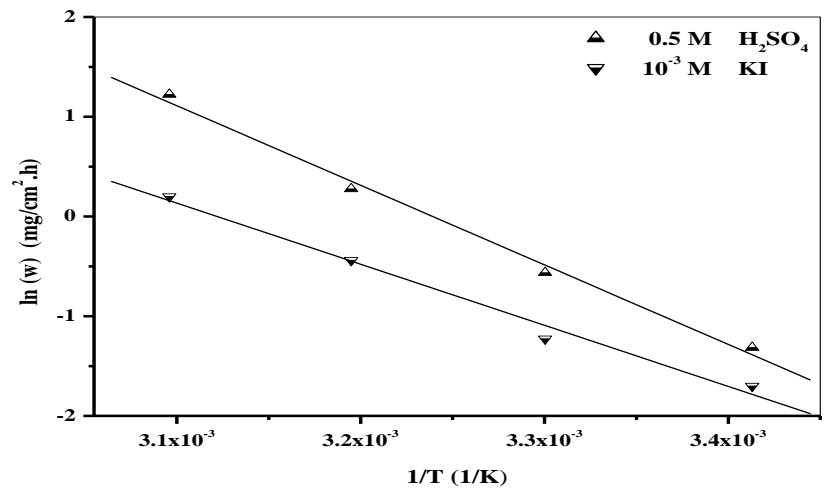

Fig. 5: Adsorption Isotherm Plots for $\mathrm{Ln}(\mathrm{W})$ Versus 1/T
Where, $\mathrm{k}$ is the constant rate and $\mu$ the transmission coefficient which represents a distance and can take a value from zero to unity. If we suppose that the corrosion rate is proportional to the constant rate, the alternative formulation of Arrhenius equation is (Singh \& Ebenso 2013):

$\mathrm{w}=\left(\mu^{\prime} \mathrm{RT} / \mathrm{Nh}\right) \exp \left(\Delta \mathrm{S}_{\mathrm{a}} / \mathrm{R}\right) \exp \left(-\Delta \mathrm{H}_{\mathrm{a}} / \mathrm{RT}\right)$

Where $h$ is plank's constant, $N$ Avogadro's number, $\Delta S_{a}$ the entropy of activation, and $\Delta \mathrm{H}_{\mathrm{a}}$ the enthalpy of activation and $\mu^{\prime}=\mathrm{B} \mu$ (B is the coefficient of proportionality). A plot of $\ln (\mathrm{w} / \mathrm{T})$ versus $1 / \mathrm{T}$ gave a straight line (Figure 6) with a slope of $-\Delta H_{a} / R$ from which the value of $\Delta \mathrm{H}_{\mathrm{a}}$ was calculated.

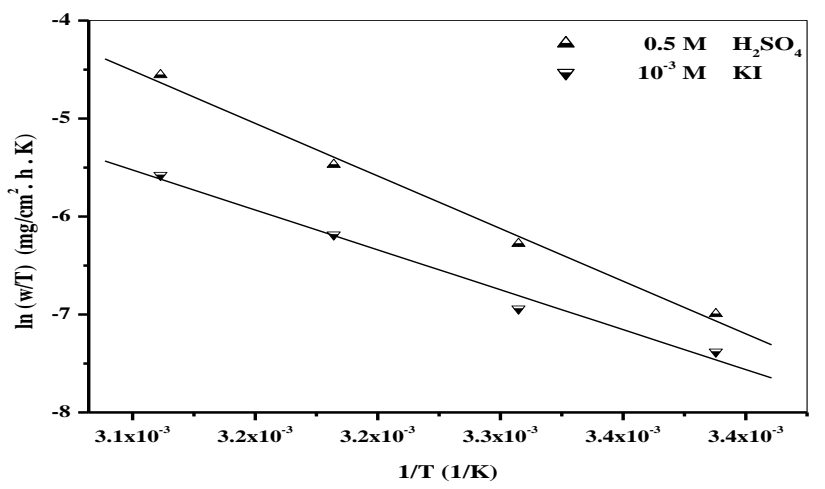

Fig. 6: Adsorption Isotherm Plots for $\operatorname{Ln}(\mathrm{W} / \mathrm{T})$ Versus 1/T

The calculated values of enthalpy are $63.79 \mathrm{~kJ} / \mathrm{mol}$ and 48.38 $\mathrm{kJ} / \mathrm{mol}$ in the absence and presence of inhibitor respectively. The positive signs of enthalpy reflect the endothermic nature of dissolution process (Sorkhabi et al. 2006, Singh et al. 2014). Moreover, the average difference value of the $\mathrm{E}_{\mathrm{a}}-\Delta \mathrm{H}_{\mathrm{a}}$ is $2.55 \mathrm{~kJ} / \mathrm{mol}$, which is approximately equal to the average value of RT $(2.52 \mathrm{~kJ} / \mathrm{mol})$. Therefore, it is indicated that the corrosion process is a unimolecular reaction as it is characterized by the following equation (Lebrini et al. 2011, Attar et al. 2014).

$\mathrm{E}_{\mathrm{a}}-\Delta \mathrm{H}_{\mathrm{a}}=\mathrm{RT}$

\section{Conclusion}

The main conclusions of the study may be presented in the following points:

- In $0.5 \mathrm{M} \mathrm{H}_{2} \mathrm{SO}_{4}$, the inhibition efficiency of potassium iodide increases with increasing the inhibitor concentration.

- The negative value of $\Delta \mathrm{G}_{\mathrm{ads}}$ is a sign of spontaneous adsorption on the metal surface.

- The adsorption of the inhibitor molecule was consistent with Temkin adsorption isotherm.

- Thermodynamic data for the inhibitor adsorption lead to suggest the occurrence may be both physical and chemical adsorption.

\section{References}

[1] Abd El-Maksoud SA (2008), The Effect of Organic Compounds on the Electrochemical Behaviour of Steel in Acidic Media. A review. International Journal of Electrochemical Science 3, 528-555.

[2] Trabanelli G (1991), Inhibitors an old remedy for a new challenge. Corrosion 47, 410-419. http://dx.doi.org/10.5006/1.3585271.

[3] Ali SA, Saeed MT \& Rahman SV (2003), The isoxazolidines: a new class of corrosion inhibitors of mild steel in acidic medium. Corrosion Science 45, 253-266. http://dx.doi.org/10.1016/S0010-938X (02)00099-9.

[4] Dananjaya SHS, Edussuriya M \& Dissanayake AS (2012), Inhibition action of lawsone on the corrosion of mild steel in acidic media. The Online Journal of Science and Technology 2, 32-36.

[5] Antonijevic MM \& Petrovic MB (2008), Copper Corrosion Inhibitors .A review. International Journal of Electrochemical Science 3, 128. 
[6] Tomić MV, Pavlović MG \& Jotanović M (2010), Protection of copper and its alloys using corrosion inhibitor-literature review. Quality of life $1,72-89$.

[7] Deyab MA (2007), Effect of cationic surfactant and inorganic anions on the electrochemical behavior of carbon steel in formation water. Corrosion Science 49, 2315-2328. http://dx.doi.org/10.1016/j.corsci.2006.10.035.

[8] Fouda AS \& Badr AH (2013), Aqueous extract of propolis as corrosion inhibitor for carbon steel in aqueous solutions. African Journal of Pure and Applied Chemistry 7, 350-359.

[9] Hamdy A \& El-Gendy NS (2013), Thermodynamic, adsorption and electrochemical studies for corrosion inhibition of carbon steel by henna extract in acid medium. Egyptian Journal of Petroleum 22, 17 25. http://dx.doi.org/10.1016/j.ejpe.2012.06.002.

[10]Poornima T, Jagannatha N \& Shetty AN (2010), Studies on corrosion of annealed and aged $18 \mathrm{Ni} 250$ grade maraging steel in sulphuric acid medium. Portugaliae Electrochimica Acta, 28, 173-188. http://dx.doi.org/10.4152/pea.201003173.

[11]Kumar P. \& Shetty AN (2013), Electrochemical investigation on the corrosion of $18 \% \mathrm{Ni} \mathrm{M} 250$ grade maraging steel under welded condition in sulfuric acid medium. Surface Engineering and Applied Electrochemistry 49 ,

253-260 http://dx.doi.org/10.3103/S1068375513030083

[12]Noor EA (2007), Temperature Effects on the Corrosion Inhibition of Mild Steel in Acidic Solutions by Aqueous Extract of Fenugreek Leaves International Journal of Electrochemical Science 2, 996-1017.

[13]Hammouti B, Zarrouk A, AL-Deyab SS \& Warad I (2011), Temperature Effect, Activation Energies and Thermodynamics of Adsorption of ethyl 2-(4-(2-ethoxy-2-oxoethyl)-2-pTolylquinoxalin-1 $(4 \mathrm{H})$ yl)Acetate on $\mathrm{Cu}$ in $\mathrm{HNO}_{3}$. Oriental Journal of Chemistry 27, 23-31.

[14]Khadraoui A, Khelifa A, Boutoumi H, Hamitouche H, Mehdaoui R, Hammouti B \& Al-Deyab SS (2014), Adsorption and Inhibitive Properties of Ruta chalepensis L Oil as a Green Inhibitor of Steel in $1 \mathrm{M}$ Hydrochloric Acid Medium. International Journal of Electrochemical Science 9, 3334-3348.

[15]Solmaz R, Mert ME, Kardas G, Yazici B \& Erbil M (2008), Adsorption and Corrosion Inhibition Effect of 1,1'-Thiocarbonyldiimidazole on Mild Steel in $\mathrm{H}_{2} \mathrm{SO}_{4}$ Solution and Synergistic Effect of Iodide Ion. Acta Physico-Chimica Sinica 24, 1185-1191. http://dx.doi.org/10.1016/S1872-1508 (08)60053-4.

[16]Chen W, Luo HQ \& Li NB (2011), Inhibition effects of 2,5dimercapto-1, 3, 4-thiadiazole on the corrosion of mild steel in sulphuric acid solution. Corrosion Science 53, 3356-3365. http://dx.doi.org/10.1016/j.corsci.2011.06.013.

[17]Zaafarany IA (2013), Corrosion Inhibition of Mild Steel in Hydrochloric Acid Solution using Cationic Surfactant Olyel-amido Derivatives. International Journal of Electrochemical Science 8, 9531-9542.

[18]Larabi L, Harek Y, Traisnel M \& Mansri A (2004), Synergistic Influence of Poly(4-Vinylpyridine) and Potassium Iodide on Inhibition of Corrosion of Mild Steel in $1 \mathrm{M} \mathrm{HCl}$. Journal of Applied Electrochemistry 833-839. http://dx.doi.org/10.1023/B:JACH.0000035609.09564.e6.

[19]Larabi L, Benali O \& Harek Y (2006), Corrosion inhibition of copper in $1 \mathrm{M} \mathrm{HNO}_{3}$ solution by $\mathrm{N}$-phenyl Oxalic Dihydrazide and Oxalic Nphenylhydrazide N'-phenylthiosemicarbazide. Portugaliae Electrochimica Acta 24,337-346. http://dx.doi.org/10.4152/pea.200603337

[20]Shukla SK, Singh AK \& Quraishi MA (2011), Corrosion Inhibition and Adsorption Properties of N-Phenylhydrazine-1,2Dicarbothioamide on Mild Steel in Hydrochloric Acid. International Journal of Electrochemical Science 6, 5779-5791.

[21]Hmamou DB, Salghi R, Zarrouk A, Messali M, Zarrok H, Errami M, Hammouti B, Bazzi L \& Chakir A (2012), Inhibition of steel corrosion in hydrochloric acid solution by chamomile extract. Der Pharma Chemica 4, 1496-1505.

[22]El Ashry EH, El Nemr A, Esawy SA \& Ragab S (2006), Corrosion inhibitors Part II: Quantum chemical studies on the corrosion inhibitions of steel in acidic medium by some triazole, oxadiazole and thiadiazole derivatives. Electrochimica Acta 51, 3957-3968. http://dx.doi.org/10.1016/j.electacta.2005.11.010.

[23]Kissi M, Bouklah M, Hammouti B \& Benkaddour M (2006), Establishment of equivalent circuits from electrochemical impedance spectroscopy study of corrosion inhibition of steel by pyrazine in sulphuric acidic solution. Applied Surface Science 252, 4190-4197. http://dx.doi.org/10.1016/j.apsusc.2005.06.035.

[24] Obot IB, Obi-Egbedi NO \& Umoren SA (2009), Antifungal drugs as corrosion inhibitors for aluminium in $0.1 \mathrm{M} \mathrm{HCl}$. Corrosion Science 51, 1868-1875. http://dx.doi.org/10.1016/j.corsci.2009.05.017.

[25]Noor EA \& Al-Moubaraki AH (2008), Thermodynamic study of metal corrosion and inhibitor adsorption processes in mild steel/1-methyl-
4[4'(-X)-styryl] pyridinium iodides/hydrochloric acid systems. Materials Chemistry and Physics 110, 145-154. http://dx.doi.org/10.1016/j.matchemphys.2008.01.028.

[26]Bilgic S \& Caliskan N (2001), An Investigation of Some Schiff Bases Ascorrosion Inhibitors for Austenite Chromium-Nickel Steel in $\mathrm{H}_{2} \mathrm{SO}_{4}$. Journal of Applied Electrochemistry 31, 79-83. http://dx.doi.org/10.1023/A:1004182329826.

[27]Umoren SA, Eduok UM \& Oguzie EE (2008), Corrosion Inhibition of Mild Steel in $1 \mathrm{M} \mathrm{H}_{2} \mathrm{SO}_{4}$ by Polyvinyl Pyrrolidone and Synergistic Iodide Additives. Portugaliae Electrochimica Acta 26, 533-546. http://dx.doi.org/10.4152/pea.200806533.

[28]Ebenso EE, Eddy NO \& Odiongenyi AO (2009), Inhibition of the Corrosion of Mild Steel by Methocarbamol. Portugaliae Electrochimica Acta 27, 13-22. http://dx.doi.org/10.4152/pea.200901013.

[29]Fekry AM \& Ameer MA (2010), Corrosion inhibition of mild steel in acidic media using newly synthesized heterocyclic organic molecules. International Journal of Hydrogen Energy 35, 7641-7651. http://dx.doi.org/10.1016/j.ijhydene.2010.04.111.

[30]Olivares O, Likhanova NV, Gomez B, Navarrete J, Lianos-Serrano ME, Arce E \& Hallen JM (2006), Electrochemical and XPS studies of decylamides of $\alpha$-amino acids adsorption on carbon steel in acidic environment. Applied Surface Science 252, 2894-2909. http://dx.doi.org/10.1016/j.apsusc.2005.04.040.

[31]Dabrowski A (2001), Adsorption-from theory to practice. Advances in Colloid and Interface Science 93, 35-224. http://dx.doi.org/10.1016/S0001-8686 (00)00082-8.

[32]Dahmani M, Et-Touhami A, Al-Deyab SS, Hammouti B, \& Bouyanzer A (2010), Corrosion Inhibition of C38 Steel in $1 \mathrm{M} \mathrm{HCl}$ : A Comparative Study of Black Pepper Extract and Its Isolated Piperine. International Journal of Electrochemical Science 5, 1060-1069.

[33] Okafor PC, Ikpi ME, Uwah IE, Ebenso EE, Ekpe UJ \& Umoren SA (2008), Inhibitory action of Phyllanthus amarus extracts on the corrosion of mild steel in acidic media. Corrosion Science 50, 2310-2317. http://dx.doi.org/10.1016/j.corsci.2008.05.009.

[34]Quraishi MA, Singh A, Singh VK, Yadav DK \& Singh AK (2010), Green approach to corrosion inhibition of mild steel in hydrochloric acid and sulphuric acid solutions by the extract of Murraya koenigii leaves. Materials Chemistry and Physics 122, 114-122. http://dx.doi.org/10.1016/j.matchemphys.2010.02.066.

[35]Quraishi MA \& Khan S (2005), Thiadiazoles-A potential class of heterocyclic inhibitors for prevention of mild steel corrosion in hydrochloric acid solution. Indian Journal of Chemical Technology 12, 576-581.

[36] Singh A, Ahamad I, Yadav DK, Singh VK \& Quraishi MA (2012), the effect of environmentally benign fruit extract of shahjan (moringa oleifera) on the corrosion of mild steel in hydrochloric acid solution. Chemical Engineering Communications, 199, 63-77. http://dx.doi.org/10.1080/00986445.2011.570390.

[37] Valle-Quitana JC \& Dominguez-Patiño GF, and Gonzalez-Rodriguez JG (2014) Corrosion Inhibition of Carbon Steel in $0.5 \mathrm{M} \mathrm{H}_{2} \mathrm{SO}_{4}$ by Phtalocyanine Blue. ISRN Corrosion 2014, 1-8,

[38]Singh A \& Ebenso EE (2013) Use of Glutamine as a New and Effective Corrosion Inhibitor for Mild Steel in $1 \mathrm{M} \mathrm{HCl} \mathrm{Solution.} \mathrm{Interna-}$ tional Journal of Electrochemical Science 8, 12874-12883

[39]Sorkhabi HA, Shabani B, Aligholipour B \& Seifzadeh D (2006), The effect of some Schiff bases on the corrosion of aluminum in hydrochloric acid solution. Applied Surface Science 252, 4039-4047. http://dx.doi.org/10.1016/j.apsusc.2005.02.148

[40]Singh P, Quraishi MA \& Ebenso EE (2014), Thiourea-Formaldehyde Polymer a New and Effective Corrosion Inhibitor for Mild Steel in Hydrochloric Acid Solution. International Journal of Electrochemical Science 9, 4900-4912.

[41]Lebrini M, Robert F \& Roos C (2011), Corrosion inhibition by Isertiacoccinea plant extract in $\mathrm{HCl}$ solution. International Journal of Electrochemical Science 6, 2630-2642.

[42] Attar T, Larabi L, Harek y (2014), Corrosion inhibition of cold rolled steel in $0.5 \mathrm{M} \mathrm{H}_{2} \mathrm{SO}_{4}$ by potassium iodide. Der Pharma Chemica 6 , 181-186. 